\title{
Visual search for letters in intact and mixed-case words and nonwords
}

\author{
TIMOTHY MCNAMARA, NICKLAS WARD, and JAMES F. JUOLA \\ University of Kansas, Lawrence, Kansas 66045
}

\begin{abstract}
College students searched for single target letters in word and unpronounceable nonword displays of four, five, or six letters in length. The displays were typed in either intact upperor lowercase form or in an alternating mixture of upper- and lowercase letters. Response times and error rates were less for words than for nonwords. Search rates, as measured by the slopes of the functions relating response time to display length, were greater for nonwords than for words. The search process apparently self-terminated for nonword displays, as the negative slope was about twice the positive slope. The positive and negative slope differences were less for words and were about equal for words in intact form. Case mixtures resulted in slower responses for words only, and this effect was apparently limited to encoding rather than to search or comparison processes. The relevance of these findings for similar results in same-different judgment tasks is discussed.
\end{abstract}

A common finding in the word recognition literature is that words are recognized more rapidly and accurately than strings of unrelated letters (e.g., Manelis, 1974; Reicher, 1969). This perceptual word-superiority effect could be due to differences in the way the letters in the strings are processed, since the orthographic redundancy in words could facilitate letter recognition processes (Massaro, 1975). Alternatively, the word advantage could be due to the use of higher order units, such as spelling patterns or even whole words, that are recognized more efficiently than are strings of independent letters.

One way to differentiate among these alternatives is to use displays that are presented in their normal visual form (either all uppercase or all lowercase letters) vs. displays that are altered in some way that preserves their orthographic structure (e.g., by mixing upperand lowercase letters). If the use of orthographic redundancy is the key to word-superiority effects, word advantages over nonwords in perception should be the same for intact and mixed-case displays. In fact, same-different judgment times for simultaneously presented letter strings are slowed more for words than for nonwords when their letters are printed in mixed case relative to intact upper- or lowercase form (Bruder, 1978; Pollatsek, Well, \& Schindler, 1975; Taylor, Miller, \& Juola, 1977). Apparently, the mixing of letter cases in words disrupts the visual familiarity of multiletter units and increases the likelihood that they must be processed letter

This research was supported by Biomedical Sciences Grant RR-07037 to the University of Kansas, National Science Foundation Grant BMS74-12801, University of Kansas General Research Fund Grant 3339-5038, and National Institute of Education Grant NIE-G-77-0010 to the third author. The first author also received support from an undergraduate research participation award from the University of Kansas. The project presented or reported herein was performed pursuant to a grant from the National Institute of Education, Department of Health, Education, and Welfare. However, the opinions expressed herein do not necessarily reflect the position or policy of the National Institute of Education, and no official endorsement by the National Institute of Education should be inferred. Send reprint requests to James F. Juola, Department of Psychology, University of Kansas, Lawrence, Kansas 66045. by letter, much as unfamiliar nonwords presumably are.

The problem for this explanation, and for the simultaneous matching task in general, is that it does not identify the processing stage or stages contributing to word advantages over nonwords. That is, word advantages could be due to the use of multiletter units during encoding or recognition of the words, but it is also possible that the presence of familiar units could facilitate later processing stages. In the simultaneous matching task, if one letter string is encoded before the other, the first must be held in memory in some form before it can be compared with the second. The comparison process itself involves encoded representations of both letter strings in memory. Both short-term retention and comparison processes could be facilitated by the use of familiar letter-cluster or whole-word units rather than individual letters. In fact, Bruder (1978) has argued that the word-superiority effect in the simultaneous matching task is due primarily to the use of familiar letter-cluster units to facilitate the comparison stage of processing, whereas Taylor et al. (1977) argued from similar data that at least part of the word advantage is due to encoding differences between words and nonwords.

From the results of earlier research (e.g, Juola, Leavitt, \& Choe, 1974; Manelis, 1974), we believe that words can be encoded or recognized more efficiently than nonword letter strings due to the presence of familiar letter clusters that are processed as units. The present study was designed to provide converging evidence for the assertion made by Taylor et al. (1977) that mixing letter cases disrupts encoding processes for words and thereby reduces the word advantage in the same-different task. We used a visual search task in the present study in which a single target letter was given on each trial followed by a word or nonword display. The subject was to make a positive response if the target was in the display and a negative response otherwise. The displays were either intact (i.e., printed in all upper- or all lowercase letters) or mixed (i.e., 
upper- and lowercase letters alternated within the strings). If the negative effect on word processing due to mixed letter cases is localized in recognition or encoding processes only, then there should be no interaction between the number of display letters and the intact vs. mixed-case variable. On the other hand, if the visual familiarity of the displays affects letter comparison time, then the slopes of the functions relating mean response times to number of letters should be steeper for mixed-case displays than for intact displays. The response times for nonwords should be unaffected by letter-case manipulations, as both encoding and comparison processes are assumed to be letter by letter in the absence of familiar letter clusters.

\section{METHOD}

The subjects were nine University of Kansas undergraduates who participated for course credit. Each subject participated in five 50-min sessions on separate days.

The stimuli consisted of 90 one- and two-syllable words and 90 nonwords, all four, five, or six letters in length. The words were selected from the Kučera and Francis (1967) word lists, with the constraints that they contain no repeated letters and that half (15) of the words at each length contain one syllable and the other half contain two syllables. The mean frequency of the selected words was about $490 /$ million. The nonwords were constructed by making irregularly spelled and unpronounceable anagrams of the words.

All of the 180 stimuli were used once each in the three lettercase conditions: intact uppercase, intact lowercase, and mixed upper- and lowercase. The mixed-case displays were equally divided into strings beginning with upper- and lowercase letters, and letter cases alternated throughout the strings. Within each cell of the design, one-third of the stimuli were selected to be used on negative trials; that is, a target letter was randomly selected from those letters not included in the display. For intact displays, the targets were presented in the same (upper or lower) case as the display letters, and half of the targets were uppercase and half lowercase for the mixed displays. The other two-thirds of the stimuli were used on positive trials, with the targets selected approximately equally often from each serial position within all conditions. Further, about half of the positive target letters in each condition physically matched one of the display letters, whereas the other half matched a display letter in name only.

The stimuli were typed onto white paper using an IBM Selectric II typewriter. In order to minimize gross differences among the display types, a relatively large lowercase font (IBM Letter Gothic) and a relatively small uppercase font (IBM Prestige Elite) were used. The stimuli were then photoenlarged to twice their normal size and individually adhered to $15.2 \times 22.9 \mathrm{~cm}$ white cards for presentation in an Iconix three-field tachistoscope. From the subjects' point of view, a five-letter item subtended a vertical visual angle of about $.3 \mathrm{deg}$ and a horizontal angle of about $1.5 \mathrm{deg}$.

Each subject viewed all 540 experimental stimuli once each over the five sessions. The first session began with 24 practice trials, and Sessions 2-5 began with 15 practice trials using materials similar to the experimental stimuli. Each trial began with a ready signal from the experimenter. The subject initiated the trial by depressing a foot switch, illuminating the target letter for $1 \mathrm{sec}$ in the center of the field of view. The target letter was immediately followed by a masking field containing a 4 by 9 grid of overlapped Xs and Os presented for $500 \mathrm{msec}$. The display followed the mask and remained in view until the subject responded by pressing one of two contact switches located under either hand. Both the assignment of positive and negative responses to the right- and left-hand switches and the sequence of experimental trials were randomly determined for each subject. The subjects were instructed to respond rapidly and accurately, and response times were recorded from the display onset until one of the response switches was pressed.

\section{RESULTS}

The results replicated similar measurements of search times for single-letter targets in horizontal strings of letters (e.g., Atkinson, Holmgren, \& Juola, 1969; Chiang \& Atkinson, 1976; Gilford \& Juola, 1976; Juola, Schadler, Chabot, \& McCaughey, 1978; Townsend \& Roos, 1973). That is, mean response times increased linearly with the number of display letters, and responses were faster on positive trials than on negative trials. Response times were also shorter when the displays were words rather than nonwords. These results are shown in Figure 1, where mean correct response times are plotted against the number of display letters. In Figure 1, the data for intact upper- and lowercase displays are combined, since the small response time advantage for lowercase letters did not interact with any other factor.

Response times were about the same for intact and mixed-case nonwords (mean times were 631 and $637 \mathrm{msec}$, respectively), but mixing letter cases in words significantly hampered search performance, with mean times of 602 and $572 \mathrm{msec}$ for mixed and intact words, respectively $[\mathrm{F}(1,8)=8.8, \mathrm{p}<.025$, for the interaction of Word vs. Nonword by Intact vs. Mixed].

The other striking feature of the data shown in Figure 1 is the discrepancy in slopes, or the effects of

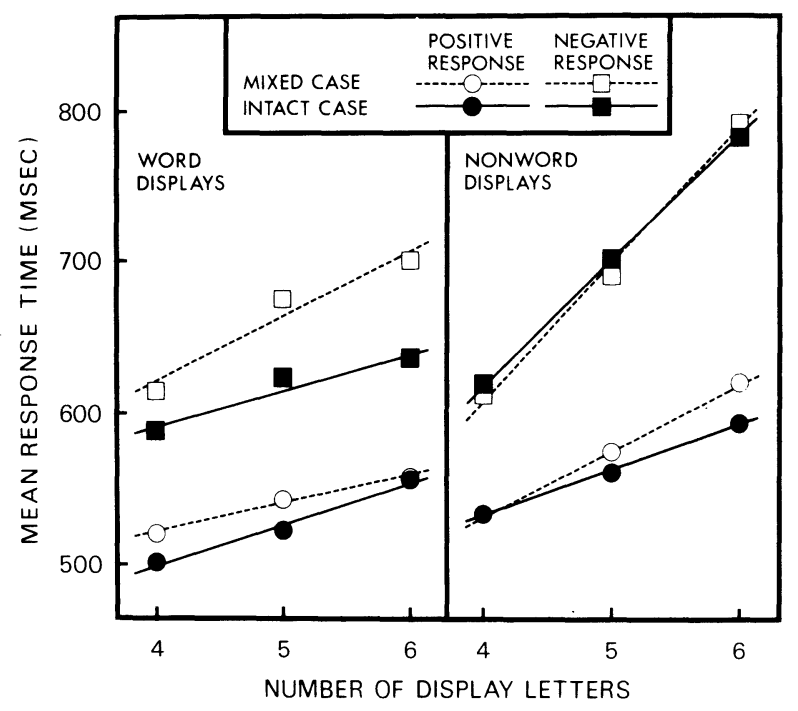

Figure 1. Mean response times plotted against the number of display letters for words (left panel) and nonwords (right panel). The straight lines are least-squares fits to the data for positive and negative responses to intact and mixed-case displays. 
number of display letters on search times, for word and nonword displays. For words, the slopes averaged about $24 \mathrm{msec} / \mathrm{letter}$ on positive trials and about $33 \mathrm{msec} / \mathrm{letter}$ on negative trials, well within the range of those found in the studies cited above. The slopes for intact words on positive trials did not differ significantly from the slopes on negative trials $[\mathrm{t}(8)=.45, \mathrm{p}>.10]$. Slopes for mixed-case words also did not differ across response type $[\mathrm{t}(8)=-1.24, \mathrm{p}>.10]$. For nonwords, however, the slopes averaged about $37 \mathrm{msec} / \mathrm{letter}$ on positive trials and about $86 \mathrm{msec} / \mathrm{letter}$ on negative trials. The slopes for intact nonwords were significantly smaller on positive trials than on negative trials $[t(8)=-3.14, p<.02]$, and the slopes for mixedcase nonwords were marginally smaller on positive trials $[t(8)=-1.91, p<.10]$. The interaction of display length and word vs. nonword was significant $[F(2,16)=8.2, p<.005]$, and the three-way interaction of these two factors with response type was marginally significant $[\mathrm{F}(2,16)=3.0, \mathrm{p}<.10]$.

Separate analyses of portions of the data revealed that there were no significant differences in response times to one- and two-syllable words, that positive responses were faster on physical-match than namematch trials, and that positive responses were somewhat faster for targets located in the leftmost serial position of the displays than in any other position.

An analysis of the error data revealed that more errors were made on nonword trials (about $4 \%$ ) than on word trials (about $2 \%$ ) $[\mathrm{F}(1,8)=12.9, \mathrm{p}<.01]$.

\section{DISCUSSION}

The results supported the hypothesis that mixed letter cases can disrupt word recognition processes by destroying the familiar units normally used in word perception. Word recognition seems to be more than a simple letter recognition and integration process, but rather depends on the familiar visual configurations of letter clusters found in common words. The lack of familiar letter clusters in the nonwords resulted in no processing differences between intact and mixed-case displays, a result consistent with letter-by-letter processing.

Although the present task is different from the simultaneous same-different task for pairs of letter strings, the results provide converging evidence for the Taylor et al. (1977) conjecture that familiarity affects encoding processes in the same-different task. Taylor et al. demonstrated a large overall word advantage and an effect of case mixtures on words but not on nonwords (see also Bruder, 1978). Both encoding and comparison processes are involved in the same-different judgment, however, and the task is not sufficiently analy tic to separate the effects of visual familiarity on these two components of performance. In the letter search task used in the present study, recognition corresponds to an encoding process common to all displays, whereas comparison processes theoretically depend on the number of display letters. Since the effects of number of letters (the slopes in Figure 1) were independent of whether the displays were mixed or intact, it appears that the initial encoding process was affected by visual familiarity but that subsequent comparison processes were not (see also Gilford \& Juola, 1976).

As a final note, it should be pointed out that the present results for the nonword displays are unusual in that the slopes for the negative response time functions are more than twice those of the positive functions. This result is more consistent with a serial self-terminating search than with an exhaustive search, which should produce equivalent slopes (Sternberg, 1966, 1975). Other studies using only intact displays and nonwords comparable to the present stimuli have consistently found nearly equivalent pcsitive and negative slopes (e.g., Atkinson et al., 1969; Juola et al., 1978). The only novelties in the present study are the combination of mixed-case displays and the requirement to search for possible name as well as physical matches for the target. The presentation of unfamiliar nonword stimuli in these conditions could have resulted in a more cautious strategy on the part of the subjects, resulting in a slower search and a tendency to self-terminate the process as soon as a match was found. These speculations do little more than describe the data, but the evidence for a self-terminating search in tasks of the present type is scanty (but see Burrows \& Murdock, 1969; Nickerson, 1966; Sternberg, Note 1), and attention should be called to the result when it is obtained.

\section{REFERENCE NOTE}

1. Sternberg, S. Scanning a persisting visual image vs. a memorized list. Paper presented at the meeting of the Eastern Psychological Association, Boston, 1967.

\section{REFERENCES}

Atkinson, R. C., Holmgren, J. E., \& Juola, J. F. Processing time as influenced by the number of elements in a visual display. Perception \& Psychophysics, 1969, 6, 321-326.

BRUDER, G. A. Role of visual familiarity in the word-superiority effects obtained with the simultaneous-matching task. Journal of Experimental Psychology: Human Perception and Performance, 1978, 4, 88-100.

Burrows, D., \& Murdock, B. B., JR. Effects of extended practice on high-speed scanning. Journal of Experimental Psychology, 1969, 82, 231-237.

Chiang, A., \& Atronson, R. C. Individual differences and interrelationships among a select set of cognitive skills. Memory \& Cognition, 1976, 4, 661-672.

GILFORD, R. M., \& JUOLA, J. F. Familiarity effects on memory search and visual search. Bulletin of the Psychonomic Society, 1976, 7, 142-144.

Juola, J. F., LeavitT, D. D., \& Choe, C. S. Letter identification in word, nonword, and single letter displays. Bulletin of the Psychonomic Society, 1974, 4, 278-280.

Juola, J. F., Schadler, M., Сhabot, R. J., \& McCaughey, M. W. The development of visual information processing skills related to reading. Journal of Experimental Child Psychology, 1978, 25, 459-476.

KuCERA, H., \& FrANCIS, W. H. Computational analysis of present-day American English. Providence: Brown University Press, 1967.

Manelis, L. The effect of meaningfulness in tachistoscopic word perception. Perception \& Psychophysics, 1974, 16, 182-192.

MASSARo, D. W. Primary and secondary recognition in reading. In D. W. Massaro (Ed.), Understanding language. New York: Academic Press, 1975.

Nickerson, R. S. Response times with a memory dependent decision task. Journal of Experimental Psychology, 1966, 72, 761-769. 
Pollatsek, A., Well, A. D., \& Schindler, R. M. Familiarity affects visual processing of words. Journal of Experimental Psychology: Human Perception and Performance, 1975, 1, 328-338.

Reicher, G. M. Perceptual recognition as a function of meaningfulness of stimulus material. Journal of Experimental Psychology, 1969, 81, 274-280.

STERNBERG, S. High-speed scanning in human memory. Science, 1966, 153, 652-654.

STERnberg, S. Memory scanning: New findings and current controversies. In D. Deutsch \& J. A. Deutsch (Eds.), Short-term memory. New York: Academic Press, 1975.
TaYlor, G. A., Miller, T. J., \& Juola, J. F. Isolating visual units in the perception of words and nonwords. Perception \& Psychophysics, 1977, 21, 377-386.

Townsend, J. T., \& Roos, R. N. Search reaction time for single targets in multiletter stimuli with brief visual displays. Memory \& Cognition, 1973, 1, 319-332.

(Received for publication June 30, 1978.) 